\title{
The effects of strain, reproductive condition, and strain of placenta donor on placentophagia in nonpregnant mice*
}

\author{
MARK B. KRISTAL $†$ and CHRISTINA L. WILLIAMS $\uparrow \uparrow$ \\ The Jackson Laboratory, Bar Harbor. Maine 04609
}

\begin{abstract}
The effects on placentophagia of strain, reproductive condition, and strain of placenta donor were observed in nonpregnant mice. Mice of the C57BL/6By and BALB/cBy strains were exposed to placentas of either strain after either no previous parturitional experience, one parturitional experience without nursing experience, or one parturitional experience with nursing experience. There was a significant effect of strain, a significant effect of reproductive condition, but no significant effect of strain of placenta donor. There was a significant interaction between strain and reproductive condition, but no significant interactions with placenta strain. It was inferred that the ability of a mouse to acquire and utilize relevant stimuli during and after parturition, in order to produce an emancipation of placentophagia from the physiological controls associated with parturition, is influenced by genotype.
\end{abstract}

Placentophagia (the eating of placenta, normally at parturition) is a little understood phenomenon, despite the fact that it occurs in most mammalian species. General hunger or food deprivation immediately prior to parturition has been eliminated as a motivating factor in the initiation of placentophagia in the rat (Kristal \& Wampler, 1973). Furthermore, in the absence of previous parturitional experience, the lateral hypothalamic area of the rat has been shown to exert a major influence on the control of placentophagia, in that damage to that area eliminates placentophagia at parturition, as well as other kinds of ingestive behavior. After parturitional experience has been acquired, damage to the lateral hypothalamic area eliminates homeostatic food and water intake, but placentophagia persists (Kristal, 1973). Likewise, nonpregnant female rats with prior parturitional experience will eat placenta following lateral hypothalamic area damage, even though homeostatic feeding and drinking have been eliminated. The incidence of placentophagia among inexperienced female rats with or without lateral hypothalamic area damage, in the same study, was found to be extremely low (Kristal, 1973). The number of rats exhibiting placentophagia among nonlesioned virgin females presented with placentas was found to be $16 \%$, whereas the number of multiparous, nonpregnant, nonlesioned females exhibiting placentophagia when presented with placentas was $100 \%$ (Kristal, 1973). It is thought that parturitional experience emancipates placentophagia from lateral hypothalamic control, and that the behavior

*This project was supported by Training Grant MH 12126, awarded to the Jackson Laboratory by the National Institute of Mental Health. The Jackson Laboratory is fully accredited by the American Association for Accreditation of Laboratory Animal Care.

$\leftarrow$ Present address: Department of Psychology, SUNY Buffalo, 4230 Ridge Lea Road, Buffalo, New York 14226.

$\dagger+$ This study was conducted during Christina Williams's tenure as an academic-year, visiting college student. Ms. Williams is presently at Williams College. We wish to express our gratitude to Basil E. Eleftheriou for his help. becomes corticalized. The influence of experience in the emancipation of other maternal behaviors from physiological (particularly hormonal) control has been demonstrated in other laboratories (Moltz \& Wiener, 1966; Moltz, Levin, \& Leon, 1969).

If placentophagia, in fact, becomes less dependent on hypothalamic influences after experience, then the process of emancipation would be expected to be dependent on the female's ability to receive, integrate, and utilize the appropriate sensory information during and after parturition. This ability would, in turn, be expected to vary with the genotype, or the consequences of the genotype, of the individual. Genotypic differences may also be invoked to account for differences in the response of virgin females toward placenta. As stated above, Kristal (1973) found that only $16 \%$ of neurally intact, virgin female rats would eat placenta, but Sachs found that $75 \%$ of the virgins he tested ate placenta (Sachs, 1969; personal communication, May 1973). The rats tested by Kristal were Sprague-Dawley albinos obtained from Carworth (CFE strain), and those tested by Sachs were Charles River albinos. It should be noted that there were other differences in procedure. Sachs presented the females with placentas to which the pups were still attached; Kristal presented the females with placentas alone. It is very likely that the difference in procedure could account for a great deal of the difference in results, but the present experiment was not designed to test this hypothesis, but rather, to evaluate the effect of genotypic differences influencing placentophagia in nonpregnant females.

Inbred strains of mice were used in the present experiment in order to control and standardize the genetic background of the animals. The study had three functions: (a) to extend to mice information on the behavior of nonpregnant females toward placenta; (b) to test the effect of genotype on the behavior of inexperienced, nonpregnant females toward placenta; and (c) to test the effect of reproductive condition and genotype on the behavior of experienced, nonpregnant 
Table 1

Number of Nonpregnant Female Mice Exhibiting Placentophagia as a Function of Reproductive Condition. Genotype. and Genotype of Placenta Donor $(\mathrm{N}=8$ Females/Cell)

\begin{tabular}{llrrr}
\hline & & \multicolumn{3}{c}{ Placenta Strain } \\
\cline { 3 - 5 } Condition & Strain & $\begin{array}{c}\text { BALB } \\
\text { cBy }\end{array}$ & $\begin{array}{c}\text { C57BL } \\
\text { VBy }\end{array}$ & Total \\
\hline \multirow{2}{*}{ Virgin } & BALB/cBy & 2 & 2 & 4 \\
& C57BL/6By & 0 & 0 & 0 \\
Primiparous NN & Total & 2 & 2 & 4 \\
(No Nursing) & BALB/cBy & 5 & 6 & 11 \\
& Total & 0 & 1 & 1 \\
Primiparous WN & BALB/cBy & 5 & 7 & 12 \\
(With Nursing) & C57BL/6By & 6 & 7 & 13 \\
& Total & 4 & 4 & 8 \\
& Total & 10 & 11 & 21 \\
& & 17 & 20 & 37 \\
\hline
\end{tabular}

females toward placenta. Two reproductive conditions in addition to the nulliparous condition were investigated. One group was allowed to give birth to their first litter, after which the pups were removed. eliminating the possibility for nursing, as well as other extended postnatal, maternal behaviors. The second experienced group was allowed to care for their young after the first parturition. An additional variable was analyzed: placental-strain preference. To investigate the possibility that among the relevant parturitional stimuli are cues directly attributable to the placenta. which are dependent on the genotype of the female producing the placenta. the females in the present experiment were tested with placenta derived from females of their own strain, or tested on placenta derived from females of the other strain.

\section{METHODS}

\section{Subjects}

Ninety-six nonpregnant female mice, 48 of which were of the BALB/CBy inbred strain and 48 of which were of the C57BL/6By inbred strain, were used. The mice were obtained from the laboratory colony maintained by B. E. Eleftheriou, at the Jackson Laboratory. At the time of testing (60-70 days of age), 16 of the females of each strain were virgins (Virgin group), 16 had given birth to one litter, but the litter was removed after the female had eaten the placenta and cleaned the pups but before she had nursed (Primiparous N.N. group), and 16 had given birth to one litter and had been allowed to nurse until the time of testing (Primiparous W.N. group). Virgin females were housed 4-5 per cage. and experienced females were housed individually subsequent to mating. At no time were the females allowed contact with parturient females. Food pellets and water were available ad lib, and females were maintained on a 7:00 a.m. to 7:00 p.m. daylight cycle. in $26^{1}=15 \times 13 \mathrm{~cm}$ transparent plastic cages containing pine shavings.

\section{Procedure}

At 8:00 a.m. on the day of testing. females. in their home cages. Were placed in a lighted. quiet room. and all food was removed from the cave. Approximately $5^{2}:-6 \mathrm{~h}$ later. each female was placed in a clear plastic cage. the bottom of which was covered by a single paper towel. Exactly 15 min later, each female received $15 \mathrm{~min}$ exposure to placenta. Placentas were obtained from donor females killed with $\mathrm{CO}_{2}$ on the last full day. of pregnancy. Placentas were frozen in $5-\mathrm{ml}$ glass vials, along with a few drops of normal saline. For use in testing, placentas and associated fluids were thawed to about $37^{\circ} \mathrm{C}$ and $1-3$ whole placentas were presented to each female in a small, untippable specimen dish. Placentas were obtained from either $B A L B / C B$ : or $C 57 \mathrm{BL} / 6 \mathrm{By}$ donors and were never mixed. Separate sets of instruments were used for each strain donor. Each test female was exposed to either $\mathrm{C} 57 \mathrm{BL} / 6 \mathrm{By}$ placenta or $\mathrm{BALB} / \mathrm{CBy}$ placenta. Females with parturitional experience (Groups Primiparous N.N. and Primiparous W.N.) were tested 10 days after parturition. It should be noted that estrous cyclicity of the female was not a controlled variable. Virgin females were cyclic; Primiparous N.N. females may or may not have been cyclic; and Primiparous W.N. females were probably in lactational acyclicity.

\section{RESULTS}

The numbers of females exhibiting placentophagia in each group of eight, are presented in Table 1 . The values in Table 1 were subjected to analysis of variance.

The effect of placenta strain was found to be not significant when tested against a residual containing the variance of interactions with placenta strain, which were found to be homogeneous by $\mathrm{F}_{\max }(\mathrm{F}=5.00, \mathrm{df}=1 / 5$, $\mathrm{p}>.05)$. The variance attributable to placenta strain as well as that attributable to the interactions with placenta strain were pooled into the residual used to test the effects of strain. reproductive condition, and the interaction between them.

The BALB/cBy strain exhibited a significantly higher incidence of placentophagia than did the $\mathrm{C} 57 \mathrm{BL} / 6 \mathrm{By}$ strain, over all three reproductive conditions $(F=$ 120.82 , df $=1 / 6, p<.001)$. Reproductive condition produced significantly different incidences of placentophagia in both strains, in that Virgin < Primiparous N.N. < Primiparous W.N. $(F=72.62, \mathrm{df}=$ $2 / 6 . \mathrm{p}<.001)$. The interaction between strain and reproductive condition was significant $(F=10.38, \mathrm{df}=$ $2 / 6, p<.025$ ), in that the greatest increase in the proportion of females exhibiting placentophagia in the $\mathrm{BALB} / \mathrm{cBv}$ strain occurred with parturition alone. but parturition plus nursing produced the greatest increase in the proportion of $\mathrm{C} 57 \mathrm{BL} / 6 \mathrm{By}$ females exhibiting placentophagia (see Fig. 1).

As an incidental observation. virgin C57BL/6By mice. when presented with placenta, frequently withdrew to the farthest corner of the cage and engaged in tail rattling.

\section{DISCUSSION}

It is evident that nonpregnant experienced mice will indeed eat placenta. The extent to which the behavior is manifested by nonpregnant mice. either before or after gaining parturitional experience. however. is subject to influences related to genotype. Whether these influences are directly genetic or are other influences correlated 
with genotype is, as yet, unknown. It is conceivable that the relationship of genotype to the acquisition and utilization of parturitional experience is a function of genetic differences in either sensory acuity or in the ability to consolidate information in the cortex. Obviously, parturitional and postnatal maternal experience has a similar effect on both strains of mice tested, as well as on rats (Kristal, 1973). However, the strains of mice differ in either the speed of utilization of relevant experiential stimuli or in the requisite attributes of the stimulus situation. For nonpregnant

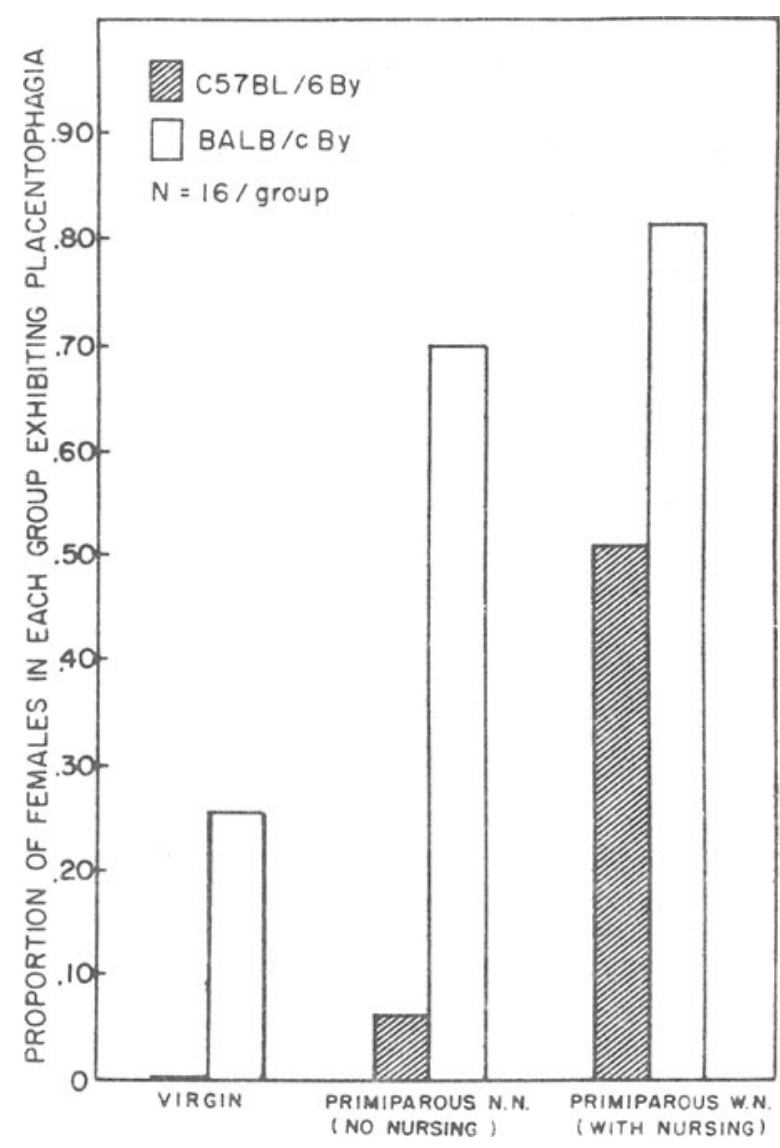

Fig. 1. Incidence of placentophagia in nonpregnant females as a function of strain and reproductive condition.
C57BL/6By mice to manifest as high a proportion of placentophagia as do nonpregnant BALB/cBy mice they seem to require more time spent being maternal, the opportunity to express a greater range of maternal behaviors, or a more prolonged hormonal environment associated with lactation. This is assumed to be necessary for the consolidation or utilization of the relevant stimuli for the emancipation of placentophagia from physiological-state dependence (parturition).

The uniqueness of placenta, as opposed to other meat substances, was thought to play an important role in the stimulus milieu at parturition. Kristal (1973) demonstrated that parturient and nonpregnant females made aphagic with lateral hypothalamic area lesions would eat placenta, but not other forms of meat such as rat liver or ground beef. The present experiment demonstrated that placenta, per se, and not a possible difference in some aspect of placental composition produced by the genotype of the placenta donor, was important. Either the two strains of placenta used did not differ in the intensity or quality of their stimulus properties, the test females could not discriminate between the two types on the basis of their sensory capabilities, or the detectable differences if they did exist were irrelevant.

\section{REFERENCES}

Kristal, M. B. Effects of lateral hypothalamic lesions on placentophagia in virgin, primiparous, and multiparous rats. Journal of Comparative \& Physiological Psychology, 1973, 84, 53-62.

Kristal, M. B., \& Wampler, R. S. Food and water intake prior to parturition in the rat. Physiological Psychology, 1973, 1, 297-300.

Moltz, H., Levin, R., \& Leon, M. Differential effects of progesterone on the maternal behavior of primiparous and multiparous rats. Journal of Comparative \& Physiological Psychology, 1969, 67, 3640.

Moltz, H., \& Wiener, E. Effects of ovariectomy on maternal behavior of primiparous and multiparous rats. Journal of Comparative \& Physiological Psychology, 1966, 62, 382-387.

Sachs, B. Behavior of maternal rats in the perinatal period. American Zoologist, 1969, 9, 1068.

(Received for publication July 17,1973 ; revision received August 24, 1973.) 